\title{
Physical and sexual abuse in orphaned compared to non- orphaned children in sub-Saharan Africa: A systematic review and meta-analysis
}

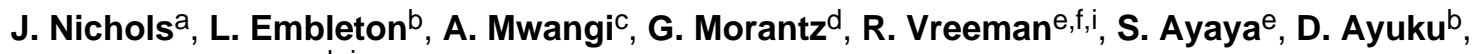 \\ and P. Braitstein ${ }^{a, g, h, i}$ \\ aUniversity of Toronto, Dalla Lana School of Public Health, University of Toronto, 155 College St., \\ Toronto, Ontario, Canada, M5T 3M7 \\ bMoi University, College of Health Sciences, School of Medicine, P.O. Box 46060301000 , \\ Eldoret, Kenya \\ 'Moi University, College of Health Sciences, Department of Behavioral Sciences, P.O. Box 4606 \\ 0301000, Eldoret, Kenya
}

dMcGill University, Department of Pediatrics, 2300 Tupper, Montreal, Quebec, Canada, H3H 1P3

eMoi University, College of Health Sciences, School of Medicine, Department of Child Health and Paediatrics, P.O. Box 46060301000 , Eldoret, Kenya

IIndiana University, School of Medicine, Department of Pediatrics, 410 W. $10^{\text {th }}$ St, Suite 1000 , Indianapolis, IN, USA IN 46202

9Moi University, College of Health Sciences, School of Medicine, Department of Medicine, P.O. Box 46060301000 , Eldoret, Kenya

hIndiana University, School of Medicine, Department of Medicine, 1001 West $10^{\text {th }}$ Street, OPW M200, Indianapolis, IN, USA 46202

'Regenstrief Institute, Inc., 410 West $10^{\text {th }}$ St, Indianapolis, IN, USA, IN 46202-3012

\section{Abstract}

This systematic review assessed the quantitative literature to determine whether orphans are more likely to experience physical and/or sexual abuse compared to non-orphans in sub-Saharan Africa (SSA). It also evaluated the quality of evidence and identified research gaps. Our search identified 10 studies, all published after 2005, from Zimbabwe, South Africa, Kenya and Uganda. The studies consisted of a total 17,336 participants (51\% female and 58\% non-orphans). Of those classified as orphans ( $n=7,315), 73 \%$ were single orphans, and $27 \%$ were double orphans. The majority of single orphans were paternal orphans (74\%). Quality assessment revealed significant variability in the quality of the studies, although most scored higher for general design than dimensions specific to the domain of orphans and abuse. Combined estimates of data suggested that, compared to non-orphans, orphans are not more likely to experience physical abuse (combined $O R=0.96,95 \%$ CI $[0.79,1.16]$ ) or sexual abuse (combined $O R=1.25,95 \%$ CI $[0.88$,

\footnotetext{
(C) 2013 Elsevier Ltd. All rights reserved.

Corresponding Author: Dr Paula Braitstein, Indiana University, Department of Medicine 1001 West 10 ${ }^{\text {th }}$ Street, OPW M200, Indianapolis, IN, USA 46202. Tel: + 254728825 620. pbraitst@iupui.edu.

Publisher's Disclaimer: This is a PDF file of an unedited manuscript that has been accepted for publication. As a service to our customers we are providing this early version of the manuscript. The manuscript will undergo copyediting, typesetting, and review of the resulting proof before it is published in its final citable form. Please note that during the production process errors maybe discovered which could affect the content, and all legal disclaimers that apply to the journal pertain.
} 
1.78]). These data suggest that orphans are not systematically at higher risk of experiencing physical or sexual abuse compared to non-orphans in sub-Saharan Africa. However, because of inconsistent quality of data and reporting, these findings should be interpreted with caution. Several recommendations are made for improving data quality and reporting consistency on this important issue.

\section{Keywords}

Orphans; sub-Saharan Africa; sexual abuse; physical abuse; abuse; systematic review

\section{Introduction}

The United Nations Children's Fund (UNICEF) estimates there are 153 million orphaned children and adolescents in the world; millions more children have been abandoned (UNICEF, 2012). The majority live in low and middle-income countries (UNICEF, 2012). Approximately 27\% have been orphaned by AIDS and two-thirds are adolescents (UNICEF, 2006, 2012). Compared to non-orphans, orphaned youth are at higher risk of HIV (Operario, Underhill, Chuong, \& Cluver, 2011), malnutrition (Miller, Gruskin, Subramanian, \& Heymann, 2007), other childhood morbidities (Amoako Johnson, Padmadas, \& Smith, 2010), and stigma and discrimination (Chuong \& Operario, 2011; Cluver \& Orkin, 2009; Monasch \& Boerma, 2004).

The numbers of orphans requiring care, together with poverty, rapid urbanization, and sociocultural issues, make it difficult for extended families to absorb these children as they traditionally would (Hosegood, Flyod, Marston, Hill, McGrath, Isingo....Zaba, 2007; Monasch \& Boerma, 2004; Rose, 2005; UNICEF, 2012). Substantial research has documented cases of intra-household discrimination and material and educational neglect among orphans in comparison to non-orphans across the continent. Orphans are less likely to attend school across Sub-Saharan Africa (SSA; Ainsworth \& Filmer, 2006; Deininger, Garcia, \& Subbarao, 2003; Makame, Ani, \& Grantham-McGregor, 2002; Monasch \& Boerma, 2004; Subbarao \& Coury, 2004). Research into intra-household discrimination demonstrates that orphans are less likely to be enrolled in school than non-orphans with whom they live (Case, Paxson, \& Ableidinger, 2004), more likely to go to bed hungry (Makame et al., 2002), and more likely to be subject to material neglect within households (Cluver \& Gardner, 2007a; Cluver \& Gardner, 2007b; Cluver, Gardner, \& Operario, 2007; Morantz, Cole, Vreeman, Ayaya, Ayuku, \& Braitstein, 2013a; Morantz, Cole, Ayaya, Ayuku, \& Braitstein, 2013b). Orphans are also more likely to be exploited than non-orphans, including being subjected to child labor (Deininger et al., 2003; Siaens, Subbarao, \& Wodon, 2003; Whetten et al., 2011) and unjust loss of assets (Deininger et al., 2003; Subbarao \& Coury, 2004).

Although increased discrimination and neglect among orphans in comparison to nonorphans has been broadly compiled and analyzed across SSA, the quantitative literature concerning physical and sexual abuse sustained by orphans in comparison to non-orphans has not. A review of qualitative research suggests that orphans are subject to greatly increased physical and sexual abuse in extended family settings (Morantz et al., 2013a). Yet, qualitative accounts of physical and sexual abuse lack the ability to quantify or draw conclusions regarding the potentially systematically heightened levels of abuse in orphans in comparison to nonorphans living in similar settings or households. If orphans are systematically at higher risk for physical and sexual abuse in addition to other forms of abuse and exploitation, this finding would add to the mounting international pressure for strengthened child protection programs and services for orphans (Clay et al., 2012). 
Thus, we aimed to conduct a systematic review and meta-analysis of the quantitative literature on orphans and abuse to determine whether and to what extent orphans are more likely to experience physical and/or sexual abuse compared to non-orphans. Physical and sexual abuses pose a serious threat to the long-term mental and physical health of children (Anda et al., 2006; Danese, 2009; Herrenkohl, Herrenkohl, Rupert, Egolf, \& Lutz, 1995; Maniglio, 2011; Mills et al., 2011; Paolucci, Genuis, \& Violato, 2001; Ramiro, Madrid, \& Brown, 2010; Scarborough, Lloyd, \& Barth, 2009; Widom, White, Czaja, \& Marmorstein, 2007). Elucidating an increased risk of physical and/or sexual abuse among a subset of children will have important implications for future policy and program planning. This systematic review objectively compiled information from a variety of sources and provides much needed insight into the extent of physical and sexual abuse sustained by orphans in SSA. It describes the strengths and weaknesses of the quality of the evidence and identifies future research needs. Overall, this work is aimed at informing policy and programs concerned with the care of orphans as well as demonstrating gaps in the available literature.

\section{Methods}

\section{Operational Definitions}

UNICEF defines an orphan as a child under the age of 18 whose mother (maternal orphan), father (paternal orphan), or both parents (double orphan) has died from any cause (UNICEF, 2006). We modified the UNICEF definition for this study to include both children (0-18) and youth (15-24), which is consistent with the definition used by the United Nations (United Nations Economic Commision for Africa [UNECA], 2011). Physical abuse was defined as an act resulting in a non-accidental physical injury, including intentional assault and unreasonable punishment (O'Toole, 2003). Sexual abuse was defined as a nonconsensual act of a sexual nature performed with a child or youth, including rape, incest, oral copulation, and penetration of the genital or anal opening by a foreign object (O'Toole, 2003). In this review, we chose to focus specifically on physical and sexual abuse. Thus, this systematic review excluded studies focused solely on emotional abuse and studies focused on more passive forms of abuse (e.g., neglect and discrimination) because of measurement challenges.

\section{Search Selection}

We searched for any published peer-reviewed studies that assessed the prevalence of physical and/or sexual abuse among children and/or youth in SSA. No registered review protocol exists for this study, although a review protocol was drafted, edited, and agreed upon by the authors of this study before the review commenced. Studies were included if they met the following inclusion criteria: (a) participants were $<25$ years old, (b) parental vital status was assessed by either the child or caregiver, (c) the definition of physical and/or sexual abuse met this study's definition of abuse, (d) a comparison between orphan and nonorphan subgroups on physical- and/or sexual abuse-related quantitative variable(s) was(were) available, (e) the study was published in English, and (f) the study assessed individuals living in SSA as per the United Nations definition of SSA. We included studies published after December $31^{\text {st }}, 1989$, because before this date HIV/AIDS prevalence within SSA had not yet reached a magnitude that disrupted social cohesion, drastically increased the proportion of orphans, and eroded the traditional kinships that often functioned as a protective safety net for orphans (UNICEF, 2003). We included the following study designs: cross-sectional, cohort, case-control, mixed-methods, and interventions that provided baseline data on physical or sexual abuse of orphans and nonorphans. We excluded studies that did not have quantitative data, dissertations, and conference abstracts. The investigators carried out all searches and conducted all procedures for study selection, quality assessment, data extraction, and analysis. 


\section{Search}

Electronic searches of Ovid MEDLINE, PsychINFO, EMBASE, Scopus, and International Bibliography of the Social Sciences (IBSS) were conducted on February 16, 2012, including studies from January $1^{\text {st }}, 1990 \mathrm{~m}$ to the second week of February 2012. No search restrictions were used. The following broad search strategy was used to search the databases: (orphan* or OVC or (orphan* and vulnerable children) or parental death or parental bereave*)

AND

(Sub-Saharan Africa or Sub-Saharan African or Africa south of the Sahara or Subsaharan Africa or Subsaharan African or developing country or developing countries or Burundi or Comoros or Djibouti or Eritrea or Ethiopia or Kenya or Madagascar or Malawi or Mauritius or Mayotte or Mozambique or Reunion or Rwanda or Seychelles or Somalia or Uganda or Tanzania or Zambia or Zimbabwe or Angola or Cameroon or Central African Republic or Chad or Congo or Democratic Republic of the Congo or Equatorial Guinea or Gabon or Sao Tome or South Sudan or Sudan or Botswana or Lesotho or Namibia or South Africa or Swaziland or Benin or Burkina Faso or Cape Verde or Cote d'Ivoire or Ivory Coast or Gambia or Ghana or Guinea or Guinea- Bissau or Liberia or Mali or Mauritania or Niger or Nigeria or Saint Helena or St Helena or Senegal or Sierra Leone or Togo or HIV* or AIDS* or human immunodeficiency virus or human immunedeficiency virus or human immunodeficiency virus or human immune-deficiency virus or acquired immunodeficiency syndrome or acquired immunedeficiency syndrome or acquired immuno-deficiency syndrome or acquired immune-deficiency syndrome or HIV Infections[MeSH] or HIV[MeSH] or HIV-2 or HIV-1)

AND

(abuse or sex or welfare or psych* or mental health or physical abuse or sex offence* or child abuse, sexual or child welfare or psychosocial deprivation or sexual abuse or child abuse or violence or incest or stress, psychological or anxiety or risk factor* or psychiatric status rating scale* or child psychology or rape* or sexual assault* or molestation* or corporal punishment* OR mental disorder* or stress disorder*, post-traum* or depression)

After duplicates were removed from all identified records, two independent reviewers (JN \& LE) screened the titles and abstracts and excluded all records that clearly did not meet the inclusion criteria. If either of the reviewers found an article to be relevant, a full-text copy of the article was obtained and its eligibility assessed independently. The references of all eligible full-text articles were hand-searched by each reviewer independently, and if either reviewer found a reference to be relevant, a full-text copy was obtained and its eligibility assessed independently by the reviewers. Any disagreements were resolved by discussion between the two reviewers. A final list of studies to be included in this systematic review was agreed upon and data extracted. Although all available resources were utilized to obtain full-text articles, we were unable to locate some full-text articles of records with eligible titles and abstracts. These records were excluded from this review (Baguma, Kyomugisha, \& Kimeze, 2005; Brookes, Shisana, \& Richter, 2004; Kinyanda, Musisi, \& Nakigudde, 2004; Nyamukapa, 2006; Wild, 2001).

\section{Data Extraction}

Data were extracted by two independent reviewers (JN \& LE) and included details about study design, study setting, population demographics, and results for all abuse variables of interest. For studies with multiple orphan subgroups (e.g. maternal and paternal orphans), all relevant data were extracted. When more than one study reported on the same sample population (Cluver, Bowes, \& Gardner, 2010; Cluver, Operario, \& Gardner, 2009; Cluver \& 
Orkin, 2009; Cluver, Orkin, Boyes, Gardner, \& Meinck, 2011), the source containing the most detailed data about sexual and physical abuse was selected for the review (Cluver et al., 2010). When it was not possible to extract the data from the publication, we contacted the authors to ask for clarification or the raw data. For three such records (Cluver et al., 2010; Fotso, Holding, \& Ezeh, 2009; Kang, Dunbar, Laver, \& Padian, 2008), additional abuse data was provided by the authors that was not presented in their published manuscripts (African Population and Health Research Center [APHRC] \& The World Bank, 2007; Cluver, unpublished; Kang, unpublished). We included the additional data in this review. For one study (APHRC \& The World Bank, 2007), we exhausted our resources and were unable to extract the sexual abuse data from this paper for use in the meta-analysis. The reviewers were not blind to any aspect of this review. Data extraction was done independently by JN and LE and then the results were compared. Any disagreements were discussed until a consensus was reached.

\section{Analysis}

Methodological quality of the selected articles was measured using an adapted critical appraisal tool for cross-sectional studies (Du Rant, 1994), which was assessed in a recent review of quality assessment tools for observational studies (Sanderson, Tatt, \& Higgins, 2007). The tool was adapted from the original tool by two reviewers (JN \& LE) to include questions specific to the systematic review objectives. We eliminated questions that were not related to the robustness of the data, including those specific to the introduction and discussion. We also removed questions specific to experimental and case-control study designs because all studies for this systematic review were cross-sectional. In addition, we added questions specific to the systematic review (e.g., was the sample selected independent of orphan status?) based on our previous experiences working with orphans and vulnerable children. In total, the tool asked five questions specific to general design, 11 questions specific to the systematic review design, and two questions specific to statistical analyses within the studies. Finally, we added a scale system to assess the completeness of each questions. A score of 2 indicated the component was fully addressed, a score of 1 indicated the component was partially addressed, and a score of 0 indicated it was not addressed at all. For the studies where additional data was provided by authors (APHRC \& The World Bank, 2007; Cluver, unpublished; Kang, unpublished) we did a quality assessment on the original manuscript and data (Cluver et al., 2010; Kang et al., 2008) unless another manuscript was provided that also included the new data (APHRC \& The World Bank, 2007). The assessment of methodological quality was used to establish the quality of studies in this research domain and to identify gaps in the literature to inform future research; it did not factor into whether studies were included in the review or in the meta-analysis. The quality assessment was done independently by JN and LE. Afterwards, the two sets of results were compared and any disagreements were discussed until a consensus was reached.

The studies were assessed according to study design, study population, and sampling methods and contextual factors such as geographic location and year of the study. Based on this assessment, we determined a meta-analysis was an appropriate analysis method to compare the overall likelihood of physical and sexual abuse of orphans to non-orphans. We performed a meta-analysis to estimate the combined odds ratio effect for physical abuse and sexual abuse. We also performed a sub-analysis of sexual abuse by performing a metaanalysis to estimate the combined odds ratio effect of forced first sex. This step was added because this variable was reported in addition to general sexual abuse in several studies.

Meta-analysis is a two-stage process involving the estimation of an appropriate summary statistic for each study followed by the calculation of a weighted average of these statistics across the studies (Deeks, Altman, \& Bradburn, 2001). Two techniques were assessed for their suitability to calculate a pooled-odds ratio in this review: the fixed-effect model 
(Mantel \& Haenszel, 1959) and the random-effects model (DerSimonian \& Laird, 1986). The fixed-effect model weights each of the studies according to the amount of information it contains, and the random-effects model incorporates the heterogeneity into the weighting. We made use of the random-effects model for this systematic review because of the heterogeneity in the definitions of abuse and the composition of the participants between studies. The participants were likely to have differed in ways that could affect the results, especially with variations in age and proportion of females included in the study sample and different socio-demographics and cultural contexts across studies.

We used the random-effects model for this systematic review and used $\mathrm{I}^{2}$ to calculate the percentage of variation between studies that is attributable to heterogeneity. Because we were interested in pooled estimates by type of abuse, subgroup analyses were performed by these characteristics. A sensitivity analysis was performed based on the results of the study quality assessment. We restricted this analysis to studies that scored $>50 \%$ for each of the types of abuse to test whether lower study quality results had an undue influence on the meta-analyses. In all the analyses, two-tailed tests were used and a probability level less than or equal to .05 was considered statistically significant. Analysis was performed using Stata 10 (Stata Corporation, College Station, TX) software.

\section{Results}

Our systematic search identified 1,341 publications (Figure 1). After the removal of duplicates, the title and abstract of each record was individually assessed to determine if it met the inclusion criteria. A total of 68 articles remained for full review; nine were selected for the final review based on the inclusion criteria. One additional article was identified through handsearching bibliographies of the selected articles. There were therefore 10 fulltext articles included in this review.

Characteristics of the studies identified are presented in Table 1. All 10 studies were published in 2006 or later. The studies identified were from four SSA countries: Zimbabwe ( $n=6$; Birdthistle et al., 2008; Howard, Matinhure, McCurdy, \& Johnson, 2006; Kang et al., 2008; Nyamukapa et al., 2008; Nyamukapa et al., 2010; Pascoe et al., 2010), South Africa ( $n$ $=2$; Cluver et al., 2010; Thurman, Brown, Richter, Maharaj, \& Magnani, 2006), Uganda ( $n$ $=1$; Musisi, Kinyanda, Nakasujja, \& Nakigudde, 2007), and Kenya $(n=1$; APHRC $\&$ The World Bank, 2007; Fotso et al., 2009). All of the studies were cross-sectional in nature. The majority $(n=6)$ of studies recruited participants from households (Birdthistle et al., 2008; Cluver et al., 2010; Fotso et al., 2009; Nyamukapa et al., 2008; Nyamukapa et al., 2010; Thurman et al., 2006), four utilized schools (Cluver et al., 2010; Howard et al., 2006; Musisi et al., 2007; Pascoe et al., 2010), and two utilized other community resources (Cluver et al., 2010; Kang et al., 2008). All studies used community-based sampling origins.

The characteristics of the study populations are presented in Table 2 . The studies ranged in sample size from 34 to 6,780 participants. The proportion of orphans varied significantly across studies (range: $31-84 \%$ ). The 10 studies comprised a total of 17,336 participants ( $46 \%$ male, $51 \%$ female, and $3 \%$ gender not reported). Approximately half of the study participants were non-orphans $(n=10,021,58 \%)$. Of those participants who were classified as orphan $(n=7,315), 73 \%$ were categorized as single orphans and $27 \%$ as double orphans. The vast majority of single orphans were paternal orphans (74\%), with maternal orphans comprising $24 \%$ of all single orphans. One study (Howard et al., 2006) did not report the proportion of maternal or paternal orphans within the single orphan study population $(n=$ $109)$; thus, for $2 \%$ of single orphans in this study population, which parent was deceased was unknown. The overall age range of individuals in all studies was 6 to 21 years. 
Table 3 presents the study quality assessment carried out to identify strengths and weaknesses among the publications. The quality assessment assessed both the general study design and study design areas specific to the research domain of abuse and orphans. For each study, a total score was calculated by summing all scores given for each question and dividing by the total possible score had the study received perfect for each applicable question. Each study received a total score and subtotal scores for general design and study design specific to this systematic review (see Table 3).

The denominator varied between studies, as not all questions were applicable to each study. Therefore, scores for each study are presented as proportions to allow for cross-study comparisons. The overall mean study score was 53\% (range: $31-75 \%$ ). Studies scored significantly higher with respect to general design with an average of 69\% (range: 20-100\%) compared to aspects specific to the systematic review with an average of $41 \%$ (range $22-67 \%)$.

The systematic review specific quality assessment points to many strengths and weaknesses that are specific to the research domain of orphans and abuse. The majority of studies $(n=8)$ clearly defined orphan status as having lost one (single orphan) or both parents (double orphan). In contrast, most studies did not explicitly define abuse. Only one of the eight studies addressing sexual abuse clearly defined it (Nyamukapa et al., 2008), and only two of the four studies addressing physical abuse clearly defined it (Cluver et al., 2010; Nyamukapa et al., 2010). Also, orphan status was only confirmed by a secondary source in one of the studies (Cluver et al., 2010).

No study reported blinding the interviewer to orphan status. Moreover, there was a lack of consistency in the study sample when measuring sexual abuse, as some studies only asked a proportion of their study population (e.g., only those who self-reported being sexually active; Birdthistle et al., 2008; Musisi et al., 2007; Thurman et al., 2006) and others asked the entire study sample (Cluver, unpublished; Howard et al., 2006; Kang, unpublished; Nyamukapa et al., 2008; Pascoe et al., 2010).

As summarized in tables $4 \mathrm{~A}, 4 \mathrm{~B}$, and $4 \mathrm{C}$, a meta-analysis was conducted to determine the combined odds ratios of the likelihood of physical and sexual abuse for orphans compared to non-orphans. Sensitivity analyses to assess whether studies with a weak quality score had an undue influence on the meta-analyses revealed that the combined effects did not differ significantly when omitting studies that scored $<50 \%$ for sexual abuse and forced first sex. No studies assessing physical abuse scored $>50 \%$, and therefore, a sensitivity analysis on this outcome was not feasible. None of the five studies that measured physical abuse individually found a significant difference between orphans and non-orphans for likelihood of physical abuse. It was determined that the heterogeneity between studies was insignificant $\left(\mathrm{I}^{2}=12.1 \%, p=.336\right)$. The combined odds ratio found that orphans are $4 \%$ less likely to experience physical abuse compared to non-orphans, although this finding was nonsignificant $(O R=0.96,95 \%$ CI $[0.79,1.16]$; Table $4 \mathrm{~A})$.

For sexual abuse, two studies (Nyamukapa et al., 2008; Nyamukapa et al., 2010) of the eight that measured sexual abuse found a significant difference between orphans and nonorphans. The eight studies had insignificant heterogeneity between them $\left(\mathrm{I}^{2}=37.7 \%, p=.129\right)$. The combined odds ratio found no significant difference in the likelihood of orphans experiencing sexual abuse compared to their non-orphan peers $(O R=1.25,95 \%$ CI [0.88, 1.78]; Table 4B). A sub-analysis of the available sexual abuse data assessed the likelihood of forced first sex of orphans compared to non-orphans. These four studies were found to have significant heterogeneity between them $\left(\mathrm{I}^{2}=73.4 \%, p=.01\right)$ with two studies finding significant differences between orphans and non-orphans in the likelihood of forced first sex 
(Pascoe et al., 2010; Thurman et al., 2006). Despite this finding, the combined odds ratio was nonsignificant $(O R=1.20,95 \%$ CI [0.66, 2.19]; Table 4C).

\section{Discussion}

\section{Main Findings}

This review aimed to assess if orphans were at a higher risk for physical and/or sexual abuse compared to their non-orphan peers in SSA. There was considerable variability in methodological quality of the studies in this review, with an overall average of 53\% (range: $31-75 \%$ ) on the scoring system adapted for this study. The majority of studies scored significantly higher in general design $(M=69 \%)$ compared to study design dimensions specific to the domain of orphans and physical and sexual abuse $(M=41 \%)$. Major weaknesses identified include the lack of a clear definition of abuse, not confirming orphan status using a secondary source, a lack of validated tools to identify and classify abuse, and the inconsistent measurement of sexual abuse regarding who is asked within the study population.

Our meta-analysis found that there were no significant differences between orphans and non-orphans with respect to the likelihood of experiencing physical abuse, sexual abuse, or forced first sex. These results should be interpreted with caution because the methodological weaknesses of the studies, including variations in abuse definitions and differences in sample populations for sexual abuse.

\section{Gaps in the Literature}

Our review has found that very few studies had physical and/or sexual abuse as primary outcomes, and all were cross-sectional in nature. Additionally, because much of the research was descriptive, the data did not control for potential confounders and was unable to identify protective and/or risk factors for either physical or sexual abuse. Moreover, the majority of studies took place in Zimbabwe and South Africa $(n=8)$ which limited the generalizability of the results to the rest of SSA. Given the findings of qualitative research (Morantz et al., 2013a), there is therefore an urgent need to expand research initiatives throughout the continent because of the high prevalence of orphanhood within the region and to conduct longitudinal studies to better understand and characterize the risks and the nature of abuse experienced by these particularly vulnerable children.

All but two of the studies identified in this review did not collect caregiver data, despite evidence that a primary caregiver is influential to the well-being of a child (Cluver \& Gardner, 2007). Literature suggests that the gender and age of the primary caregiver, along with their relation to the child (e.g. uncle, grandmother) and the orphan subgroup of the child, influence the vulnerability of the orphan to one or more forms of abuse (Foster \& Williamson, 2000; Ntozi, 1997; Nyambedha, Wandibba, \& Aagaard-Hansen, 2003; Oleke, Blystad, Moland, Rekdal, \& Heggenhougen, 2006). For example, orphans living with a stepmother are especially vulnerable to discrimination and care deprivation, as females are typically responsible for child-rearing in SSA and may resent caring for orphans and/or prioritize their own children (Case \& Paxson, 2000; Oleke et al., 2006). In understanding who the primary caregiver is, the literature would uncover the living situation(s) that put a child at higher risk of abuse within the context of SSA.

Lastly, this review did not include any studies that sampled children living in institutions, which highlights the current focus of the quantitative literature on abuse and orphans on those living within extended family settings. Institutions often care for highly vulnerable children including those without an adult caregiver and those who have survived one or 
more forms of maltreatment (Morantz, Cole, Ayaya, Ayuku, \& Braitstein, 2013b). As children in institutions may differ significantly from those within extended family situations, future research into the prevalence of abuse within this model of care is needed.

\section{Limitations}

There are several important limitations to note when interpreting the results of our findings. Firstly, there are limitations with the methodology used in this review. As the review only included studies published in English, it is possible that some studies on orphans and abuse have been excluded. Although the exclusion of grey literature ensured all studies had been peerreviewed and employed ethical considerations when working with this vulnerable population, there is an increased risk that the results have been influenced by publication bias and/or that data published in organizational reports meeting the inclusion criteria have been excluded. Secondly, there are issues with respect to the quality and methodologies used in many of the identified studies that raise important limitations for discussion.

An initial aim of this review was to assess if there were differences in the likelihood of experiencing physical and/or sexual abuse between different subgroups of orphans (maternal orphans, paternal orphan, single orphan, double orphan, AIDS-orphan). This was not possible because of a lack of consistency in measurement, analysis, and/or reporting of these subgroups. Assessing the differences in likelihood of physical and/or sexual abuse among these subgroups is important as research has demonstrated differences in development, discrimination, and neglect. It has been found that maternal female orphans in SSA are significantly different than paternal female orphans with respect to negative reproductive health outcomes and education enrollment rates (Gregson et al., 2005; Kang et al., 2008). Other literature has found differences between single and double orphans with respect to their current primary caregiver, psychosocial wellbeing, and perceived available support (Howard et al., 2006; Karimli, Ssewamala, \& Ismayilova, 2012).

Moreover, in our review, only one study distinguished between AIDS orphans and those orphaned by other causes (Cluver et al., 2010). Qualitative research has demonstrated that AIDS orphans experience AIDS-related stigma and discrimination, not experienced by their other orphan peers (Morantz et al., 2013b; Strode \& Barrett-Grant, 2001). The high prevalence of HIV/AIDS and resulting large number of AIDS orphans in SSA makes this distinction extremely important for physical and sexual abuse research in this region. It is therefore important for future studies to distinguish between these subgroups to assess the role orphan type and AIDS-specific factors play in the prevalence of child physical and sexual abuse.

Another limitation of this review is the high likelihood of under reporting of physical and/or sexual abuse by study participants (Taylor Buckingham \& Daniolos, 2013; Powell, 1991). It is unknown if there is differential misclassification of abuse exposure between orphans and non-orphans due to underreporting.

The methodological quality assessment showed that almost all studies did not confirm orphan status using a second source creating the potential for non-differential misclassification bias as there is a degree of inaccuracy that characterizes how information is obtained from both study groups. This would bias results towards the null and may hide true differences in the likelihood of abuse between orphan and non-orphans (Szklo \& Nieto, 2006). Additionally, no study reported blinding the interviewer to orphan status which may have created interviewer bias. This is especially relevant given the high prevalence of orphanhood in SSA and the resulting high likelihood of data collectors having some sort of personal connection to orphanhood. 
Our review demonstrates that there is a clear need to create a standardized definition for physical and sexual abuse within the context of SSA. Limited studies clearly reported their definition of physical and/or sexual abuse and, of those that did, there was substantial variation across studies. It is especially important to define physical abuse within this context because the high levels of corporal punishment that occurs within homes and schools in many SSA countries (Cappa \& Khan, 2011; United Nations, 2006). This high prevalence may result in a normalization of the practice so that the victim and/or perpetrator(s) may accept physical abuse as normal, necessary for good behaviour, and/or inevitable, meaning they do not conceptualize the act as physical abuse (Cappa \& Khan, 2011; United Nations, 2006). A clear and culturally appropriate definition of physical abuse as well as sexual abuse is necessary to ensure proper measurement of these sensitive variables. We also recommend designing studies that adhere to existing international definitions of childhood and young adulthood (UNECA, 2011) and orphanhood (UNICEF, 2006) to help increase standardization across future studies.

In addition to standardized definitions, this review points to the need for standardized measures of physical and sexual abuse, as only 1 of 4 and 2 of 8 of the studies used a validated tool to measure physical and sexual abuse, respectively. The development of valid and reliable tools and of corresponding data collection protocols, which are founded on standardized definitions, would help these sensitive topics to be investigated in culturally and age appropriate ways. We also recommend consulting with those who are trained and are experienced working with the local target population (e.g. social workers, community health workers) to leverage their practical and cultural knowledge to further help ensure culture and age appropriateness.

Lastly, we recommend piloting the tools and procedures before beginning the study. Acknowledging all studies identified in this review has some methodological issues, we suggest reviewing the study design and methodology in Cluver et al. (2010) as a reference for future studies based on our quality assessment. Furthermore, standardized measures would help address other methodological issues this review has identified. Sexual abuse measures were often asked to only a subset of the study population, which reduces the internal and external validity within the study as well as introduces greater variability between studies. In addition, this reduces the comparability of sexual abuse with measures of other forms of child abuse. The measurement of sexual abuse in 4 of the 8 studies was asked only of those participants who had ever engaged in sexual intercourse/were sexually active. Sexual abuse may not always involve sexual intercourse nor does it require the participant to be sexually active.

Additionally, participants who have experienced sexual abuse may not consider themselves sexually active or having engaged in sexual activity if they did not give their consent. Any measure of sexual abuse should be asked of the entire sample. It is essential that any measurement tool include a timeline for the abuse since current measurement lacked an indication of when the abuse occurred, meaning it is unknown if the abuse happened prior to or after the individual was orphaned.

Also, physical and/or sexual abuse was often combined in studies with other forms of abuse, including neglect. There is a need to measure physical and sexual abuse separately from neglect and other forms of maltreatment to understand if orphans are at a systematically higher risk of abuse and, if so, what types of abuse they are experiencing differentially to properly inform practice and policy. Standardized tools may encourage researchers to assess these variables separately from other forms of child abuse. 
Lastly, in order to understand the relationship between abuse and orphanhood, the temporal sequence of these two variables must be known. Unfortunately, the current literature makes this impossible as all of the studies are cross-sectional thus can only show associations between abuse and orphan status. This review therefore highlights the need for future research to utilize a cohort study design.

\section{Conclusion}

Despite significant qualitative research reporting increased abuse among orphans, the metaanalysis of the quantitative literature in this systematic review found no significant difference in the likelihood of experiencing physical and sexual abuse between orphans and nonorphans within SSA. It is important to highlight the relatively small amount of quantitative literature available that explores the relationship between orphanhood and physical and/or sexual abuse. Furthermore, the review identified multiple limitations to the data including the definition and measurement of abuse. To design effective policy and practice responses, we need a much clearer understanding of abuse among children and youth within the region. Future research needs to utilize standardized definitions and measurements of physical and sexual abuse within longitudinal studies across multiple countries within SSA. This will help us to understand the true risk of abuse among children and youth in SSA as well as factors associated with these forms of abuse and the temporal sequence of abuse and orphanhood. Because of the conflicting qualitative and quantitative literature and the limitations of the current quantitative data, it remains unclear if orphans are more likely to experience physical and/or sexual abuse compared to non-orphans in SSA settings.

\section{Acknowledgments}

We thank all authors who provided us with further details about their studies, and who replied to our queries regarding additional data.

Funding: The project described was supported in part by Award Number R01HD060478 from the Eunice Kennedy Shriver National Institute Of Child Health \& Human Development. The content is solely the responsibility of the authors and does not necessarily represent the official views of the Eunice Kennedy Shriver National Institute of Child Health \& Human Development or the National Institutes of Health.

\section{References}

African Population and Health Research Center (APHRC), \& The World Bank. The plight of orphans and vulnerable children in nairobi urban slums in the face of HIV/AIDS. Nairobi, Kenya: APHRC; 2007.

Ainsworth M, Filmer D. Inequalities in children's schooling: AIDS, orphanhood, poverty, and gender. World Development. 2006; 34:1099-1128.

Amoako Johnson F, Padmadas SS, Smith PW. Orphanhood and vulnerability: A conduit to poor child health outcomes in Rwanda. AIDS Care. 2010; 22:314-323. [PubMed: 20390511]

Anda RF, Felitti VJ, Bremner JD, Walker JD, Whitfield C, Perry BD, et al. Giles WH. The enduring effects of abuse and related adverse experiences in childhood. A convergence of evidence from neurobiology and epidemiology. European Archives of Psychiatry and Neurological Sciences. 2006; 256:174-186.

Baguma P, Kyomugisha E, Kimeze SN. Psychosocial needs assessment of AIDS orphans in Uganda: A case study in Masaka district. Mental Health and Psychotherapy in Africa. 2005:366-418.

Birdthistle IJ, Floyd S, Machingura A, Mudziwapasi N, Gregson S, Glynn JR. From affected to infected? Orphanhood and HIV risk among female adolescents in urban Zimbabwe. AIDS. 2008; 22:759-766. [PubMed: 18356606]

Brookes, H.; Shisana, O.; Richter, L. The National Household HIV Prevalence and Risk Survey of South African Children. Cape Town, Africa: Human Science Research Council; 2004. 
Cappa C, Khan SM. Understanding caregivers' attitudes towards physical punishment of children: Evidence from 34 low- and middle-income countries. Child Abuse \& Neglect. 2011; 35:1009-1021. [PubMed: 22152701]

Case, A.; Paxson, CH. Mothers and others: Who invests in children's health?. Cambridge, MA: National Bureau of Economic Research; 2000.

Case A, Paxson C, Ableidinger J. Orphans in Africa: Parental death, poverty, and school enrollment. Demography. 2004; 4:483-508. [PubMed: 15461011]

Chuong C, Operario D. Challenging household dynamics: Impact of orphanhood, parental absence, and children's living arrangements on education in South Africa. Global Public Health. 2011; 7:42-57. [PubMed: 21644120]

Clay R, CdeBaca L, De Cock KM, Goosby E, Guttmacher A, Jacobs S, et al. Steinberg D. A call for coordinated and evidence-based action to protect children outside of family care. Lancet. 2012; 379(9811):e6-8. [PubMed: 22166902]

Cluver L. Data Set. unpublished.

Cluver L, Bowes L, Gardner F. Risk and protective factors for bullying victimization among AIDSaffected and vulnerable children in South Africa. Child Abuse \& Neglect. 2010; 34:793-803. [PubMed: 20880588]

Cluver L, Gardner F. Risk and protective factors for psychological well-being of children orphaned by AIDS in Cape Town: A qualitative study of children and caregivers' perspectives. AIDS Care. 2007a; 19:318-325. [PubMed: 17453564]

Cluver L, Gardner F. The mental health of children orphaned by AIDS: A review of international and southern African research. Journal of Child and Adolescent Mental Health. 2007b; 19:1-17.

Cluver L, Gardner F, Operario D. Psychological distress amongst AIDS-orphaned children in urban South Africa. Journal of Child Psychology and Psychiatry. 2007; 48:755-763. [PubMed: 17683447]

Cluver L, Operario D, Gardner F. Parental illness, caregiving factors and psychological distress among children orphaned by acquired immune deficiency syndrome (AIDS) in South Africa. Vulnerable Children and Youth Studies. 2009; 4:185-198.

Cluver L, Orkin M. Cumulative risk and AIDS-orphanhood: Interactions of stigma, bullying, and poverty on child mental health in South Africa. Social Science \& Medicine. 2009; 69:1186-1193. [PubMed: 19713022]

Cluver L, Orkin M, Boyes M, Gardner F, Meinck F. Transactional sex amongst AIDS-orphaned and AIDS-affected adolescents predicted by abuse and extreme poverty. Journal of Acquired Immune Deficiency Syndromes. 2011; 58:336-343. [PubMed: 21857361]

Danese A, Moffitt TE, Harrington H, Milne BJ, Polanczyk G, Pariante CM, et al. Caspi A. Adverse childhood experiences and adult risk factors for age-related disease: depression, inflammation, and clustering of metabolic risk markers. Archives of Pediatrics and Adolescent Medicine. 2009; 163:1135-1143. [PubMed: 19996051]

Deeks JJ, Altman DG, Bradburn MJ. Statistical methods for examining heterogeneity and combining results from several studies in meta-analysis. 2001

Deininger K, Garcia M, Subbarao K. AIDS-induced orphanhood as a systemic shock: Magnitude, impact, and program interventions in Africa. World Development. 2003; 31:1201-1220.

DerSimonian R, Laird N. Meta-analysis in clinical trials. Controlled Clinical Trials. 1986; 7:177-188. [PubMed: 3802833]

Du Rant R. Checklist for the evaluation of research articles. Journal of Adolescent Health. 1994; 15:48. [PubMed: 8204635]

Foster G, Williamson J. A review of current literature on the impact of HIV/AIDS on children in subSaharan Africa. AIDS. 2000; 14:S275-S284. [PubMed: 11086871]

Fotso JC, Holding PA, Ezeh AC. Factors conveying resilience in the context of Urban poverty: The case of orphans and vulnerable children in the informal settlements of Nairobi, Kenya. Child and Adolescent Mental Health. 2009; 14:175-182.

Gregson S, Nyamukapa CA, Garnett GP, Wambe M, Lewis JJ, Mason PR, et al. Anderson RM. HIV infection and reproductive health in teenage women orphaned and made vulnerable by AIDS in Zimbabwe. AIDS Care. 2005; 178:785-794. [PubMed: 16120495] 
Herrenkohl EC, Herrenkohl RC, Rupert LJ, Egolf BP, Lutz JG. Risk factors for behavioral dysfunction: The relative impact of maltreatment, SES, physical health problems, cognitive ability, and quality of parent-child interaction. Child Abuse \& Neglect. 1995; 19:191-203. [PubMed: 7780781]

Hosegood V, Floyd S, Marston M, Hill C, McGrath N, Isingo R, et al. Zaba B. The effects of high HIV prevalence on orphanhood and living arrangements of children in Malawi, Tanzania, and South Africa. Population Studies. 2007; 61:327-336. [PubMed: 17979006]

Howard B, Matinhure N, McCurdy SA, Johnson GA. Psychosocial disadvantage: Preparation, grieving, remembrance and recovery for orphans in eastern Zimbabwe. African Journal of AIDS Research. 2006; 5:71-83.

Howard BH, Phillips CV, Matinhure N, Goodman KJ, McCurdy SA, Johnson CA. Barriers and incentives to orphan care in a time of AIDS and economic crisis: A cross-sectional survey of caregivers in rural Zimbabwe. BMC Public Health. 2006; 6:27. [PubMed: 16469104]

Kang M. Data Set. unpublished.

Kang M, Dunbar M, Laver S, Padian N. Maternal versus paternal orphans and HIV/STI risk among adolescent girls in Zimbabwe. AIDS Care. 2008; 20:214-217. [PubMed: 18293132]

Karimli L, Ssewamala FM, Ismayilova L. Extended families and perceived caregiver support to AIDS orphans in Rakai district of Uganda. Children \& Youth Services Review. 2012; 34:1351-1358. [PubMed: 23188930]

Kinyanda E, Musisi S, Nakigudde J. Psychosocial problems of HIV/AIDS orphans in Uganda. Makerere Medical Journal. 2004; 37

Makame V, Ani C, Grantham-McGregor S. Psychological well-being of orphans in Dar El Salaam, Tanzania. Acta Paediatrica. 2002; 91:459-465. [PubMed: 12061364]

Maniglio R. The role of child sexual abuse in the etiology of suicide and non-suicidal self-injury. Acta Psychiatrica Scandinavica. 2011; 124:30-41. [PubMed: 20946202]

Mantel N, Haenszel W. Statistical aspects of the analysis of data from retrospective studies of disease. Journal of the National Cancer Institute. 1959; 22:719-748. [PubMed: 13655060]

Miller CM, Gruskin S, Subramanian SV, Heymann J. Emerging health disparities in Botswana: Examining the situation of orphans during the AIDS epidemic. Social Science \& Medicine. 2007; 64:2476-2486. [PubMed: 17442471]

Mills R, Alati R, O'Callaghan M, Najman JM, Williams GM, Bor W, Strathearn L. Child abuse and neglect and cognitive function at 14 years of age: Findings from a birth cohort. Pediatrics. 2011; 127:4-10. [PubMed: 21135010]

Monasch R, Boerma JT. Orphanhood and childcare patterns in sub-Saharan Africa: An analysis of national surveys from 40 countries. Aids. 2004; 18(Suppl. 2):S55-S65. [PubMed: 15319744]

Morantz G, Cole D, Vreeman R, Ayaya S, Ayuku D, Braitstein P. Child abuse and neglect among orphaned children and youth living in extended families in sub-Saharan Africa: What have we learned from qualitative inquiry? Vulnerable Children and Youth Studies: An International Interdisciplinary Journal for Research, Policy, and Care. 2013a10.1080/17450128.2013.764476

Morantz G, Cole DC, Ayaya S, Ayuku D, Braitstein P. Maltreatment experiences and associated factors prior to admission to residential care: A sample of institutionalized children and youth in western Kenya. Child Abuse \& Neglect. 2013b doi:S0145-2134(12)00252-9 [pii]10.1016/j.chiabu. 2012.10.00.

Musisi S, Kinyanda E, Nakasujja N, Nakigudde J. A comparison of the behavioral and emotional disorders of primary school-going orphans and non-orphans in Uganda. African Health Sciences. 2007; 7:202-213. [PubMed: 21499485]

Ntozi JPM. Effects of AIDS on Children: The Problem of Orphans in Uganda. Health Transition Review. 1997; 7:S23-S40.

Nyambedha EO, Wandibba S, Aagaard-Hansen J. Changing patterns of orphan care due to the HIV epidemic in western Kenya. Social Science \& Medicine. 2003; 57:301-311. [PubMed: 12765710]

Nyamukapa, CA. Psychosocial disorders in orphans and vulnerable children in Zimbabwe; Paper presented at the Zimbabwe National OVC Research Conference; Harare, Zimbabwe. 2006 Apr. 
Nyamukapa CA, Gregson S, Lopman B, Saito S, Watts HJ, Monasch R, Jukes MC. HIV-associated orphanhood and children's psychosocial distress: theoretical framework tested with data from Zimbabwe. American Journal of Public Health. 2008; 98:133-141. [PubMed: 18048777]

Nyamukapa CA, Gregson S, Wambe M, Mushore P, Lopman B, Mupambireyi Z, et al. Jukes MC. Causes and consequences of psychological distress among orphans in eastern Zimbabwe. AIDS Care. 2010; 22:988-996. [PubMed: 20552465]

Operario D, Underhill K, Chuong C, Cluver L. HIV infection and sexual risk behaviour among youth who have experienced orphanhood: Systematic review and meta-analysis. Journal of the International AIDS Society. 2011; 14:25. [PubMed: 21592368]

O'Toole, M. Miller-Kaeane encyclopedia \& dictionary of medicine, nursing \& allied health. 7 th. Philadelphia, PA: W.B. Saunders; 2003.

Oleke C, Blystad A, Moland KM, Rekdal OB, Heggenhougen K. The varying vulnerability of African orphans: The case of the Langi, northern Uganda. Childhood: A Global Journal of Child Research. 2006; 13:267-284.

Paolucci EO, Genuis ML, Violato C. A meta-analysis of the published research on the effects of child sexual abuse. The Journal of Psychology: Interdisciplinary and Applied. 2001; 135:17-36.

Pascoe SJ, Langhaug LF, Durawo J, Woelk G, Ferrand R, Jaffar S, Hayes R, Cowan FM. Increased risk of HIV-infection among school-attending orphans in rural Zimbabwe. AIDS Care. 2010; 22:206-220. [PubMed: 20390499]

Powell MB. Investigating and reporting child sexual abuse: Review and recommendations for clinical practice. Australia Psychologist. 1991; 26(2):77-83.

Ramiro LS, Madrid BJ, Brown DW. Adverse childhood experiences (ACE) and health-risk behaviors among adults in a developing country setting. Child Abuse \& Neglect. 2010; 34:842-855. [PubMed: 20888640]

Rose L. Orphans' land rights in post-war Rwanda: The problem of guardianship. Development and Change. 2005; 36:911-936.

Sanderson S, Tatt ID, Higgins JPT. Tools for assessing quality and susceptibility to bias in observational studies in epidemiology: A systematic review and annotated bibliopgrahy. International Journal of Epidemiology. 2007; 36:666-676. [PubMed: 17470488]

Scarborough AA, Lloyd EC, Barth RP. Maltreated infants and toddlers: predictors of developmental delay. Journal of Developmental \& Behavioral Pediatrics. 2009; 30:489-498. [PubMed: 19898247]

Siaens, C.; Subbarao, K.; Wodon, Q. Are orphans especially vulnerable? Evidence from Rwanda. Washington, DC: The World Bank; 2003.

Strode, A.; Barrett-Grant, K. The role of stigma and discrimination in increasing the vulnerability of children and youth infected with and affected by HIV/AIDS - Research report. Arcadia, South Africa: Save the Children; 2001.

Subbarao, K.; Coury, D. Reaching out to Africa's orphans: A framework for public action. Washington, DC: The International Bank for Reconstruction and Development and The World Bank; 2004.

Szklo, M.; Nieto, J. Epidemiology: Beyond the basics. 2nd. Sudbury, MA: Jones and Bartlett; 2006.

Taylor Buckingham E, Daniolos P. Longitudinal outcomes for victims of child abuse. Current Psychiatry Reports. 2013; 15:342. [PubMed: 23307564]

Thurman TR, Brown L, Richter L, Maharaj P, Magnani R. Sexual risk behavior among South African adolescents: Is orphan status a factor? AIDS \& Behavior. 2006; 10:627-635. [PubMed: 16838071]

United Nations Economic Commission For Africa (UNECA). African youth report 2011: Addressing the youth education and employment nexus in the new global economy. Addis Ababa, Ethiopia: UNECA; 2011.

United Nations Children's Fund (UNICEF). Africa's orphaned generations. New York, NY: UNICEF; 2003.

United Nations Children's Fund (UNICEF). Africa's orphaned and vulnerable generations: Children affected by HIV/AIDS. New York, NY: UNICEF; 2006.

United Nations Children's Fund (UNICEF). The state of the world's children: Urbanization. Geneva, Switzerland: UNICEF; 2012. 
Whetten R, Messer L, Ostermann J, Whetten K, Pence BW, Buckner M, et al. O'Donnell K. Child work and labour among orphaned and abandoned children in five low and middle income countries. BMC International Health and Human Rights. 2011; 11:1-10. [PubMed: 21232140]

Widom CS, White HR, Czaja SJ, Marmorstein NR. Long-term effects of child abuse and neglect on alcohol use and excessive drinking in middle adulthood. Journal of Studies on Alcohol and Drugs. 2007; 68:317-326. [PubMed: 17446970]

Wild L. The psychosocial adjustment of children orphaned by AIDS. Southern African Journal of Child and Adolescent Mental Health. 2001; 13:3-22. 

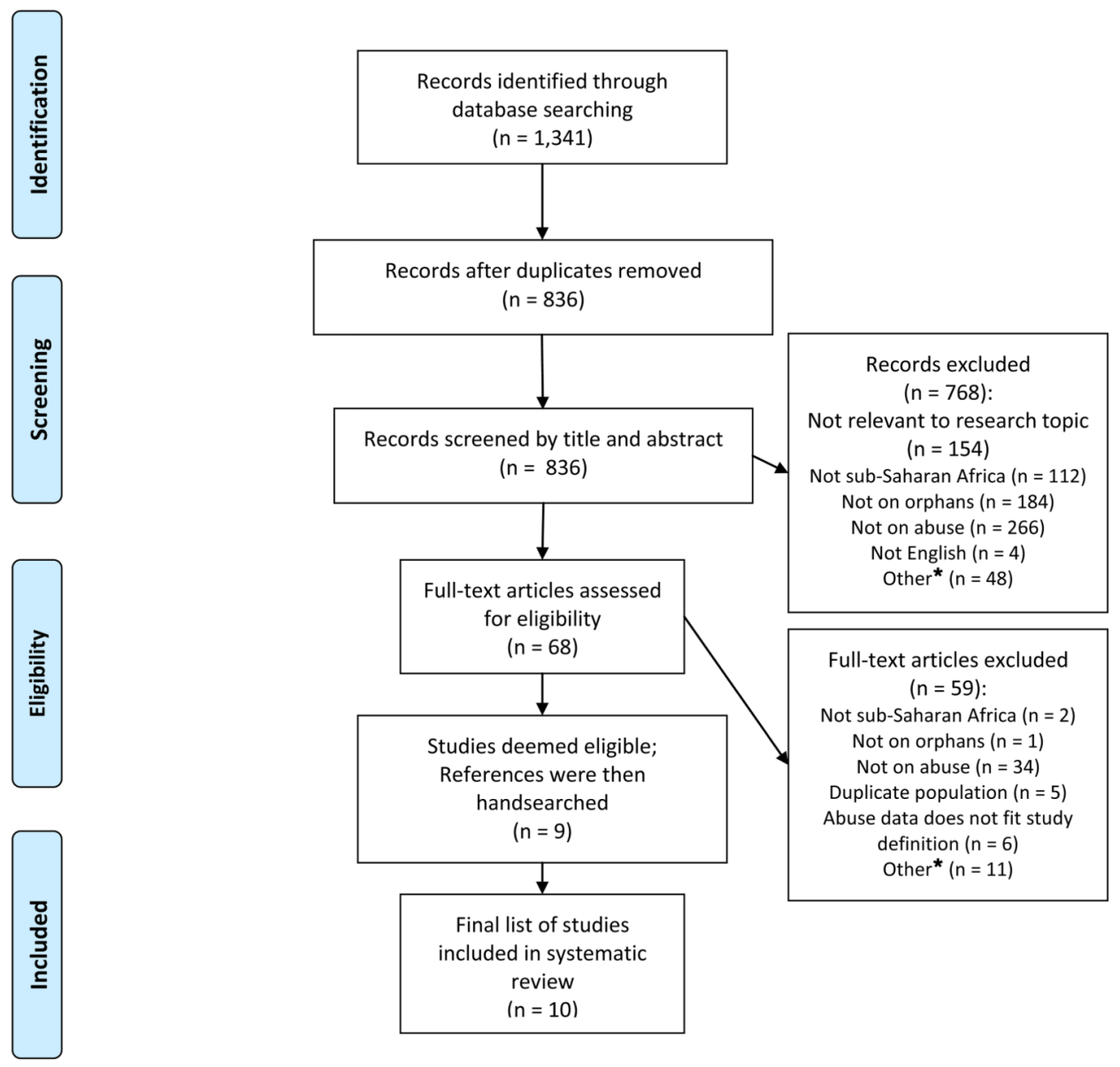

Fig 1. PRISMA 2009 Flow Diagram

*Other includes articles that lacked original data, were reported in an ineligible format (e.g. book, dissertation), lacked a comparison group, or reported only qualitative data. 


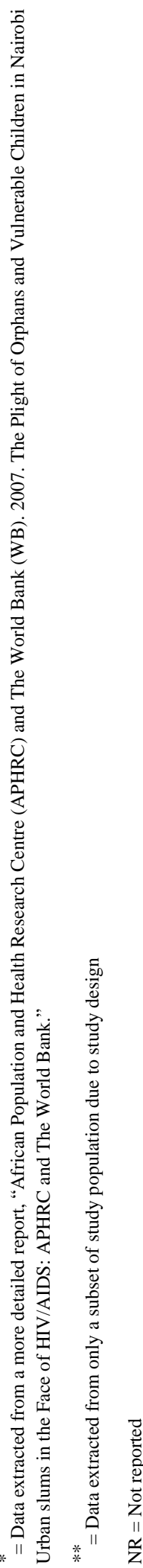

Child Abuse Negl. Author manuscript; available in PMC 2015 February 01. 


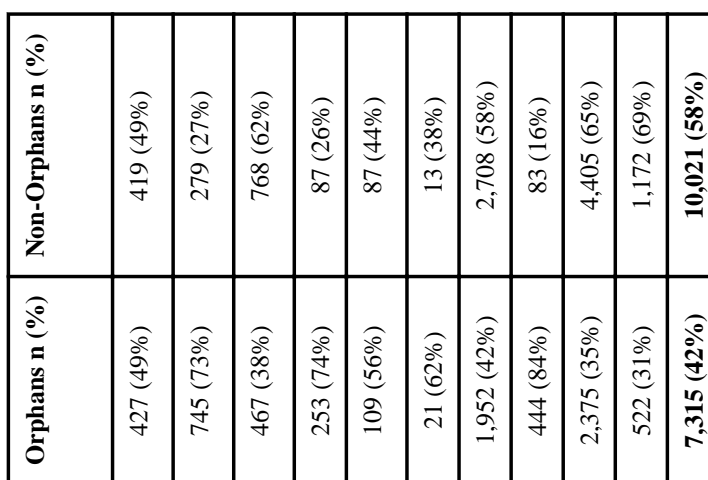

N
$\frac{0}{0}$
$\frac{0}{}$

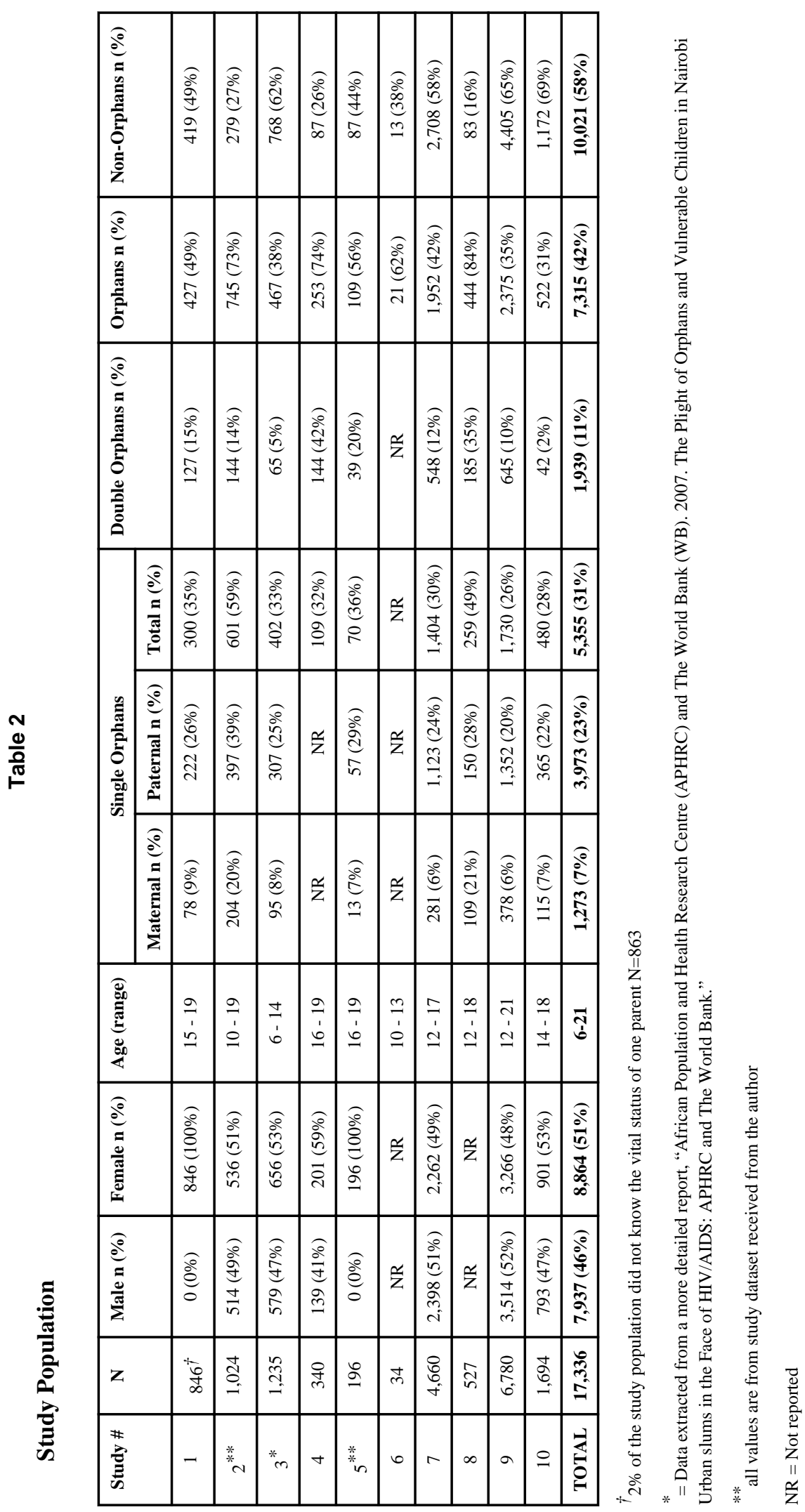

Child Abuse Negl. Author manuscript; available in PMC 2015 February 01. 


\begin{tabular}{|c|c|c|c|c|c|c|c|c|c|c|c|c|c|c|c|c|c|c|c|c|c|c|c|c|}
\hline & $\Theta$ & $\mathrm{d}$ & $\alpha$ & $N$ & $N$ & $N$ & 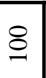 & $\sim$ & $\overleftrightarrow{\mathrm{z}}$ & - & $\alpha$ & $\overleftrightarrow{\mathrm{z}}$ & $\alpha$ & $\mathrm{N}$ & 0 & $\overleftrightarrow{\mathrm{z}}$ & 0 & $\overleftrightarrow{\mathrm{z}}$ & 0 & 0 & in & $\sim$ & $\sim$ & $\approx$ \\
\hline & $a$ & $\sim$ & $\sim$ & $N$ & $\bar{z}$ & & 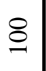 & $\sim$ & $\overleftarrow{z}$ & - & $N$ & 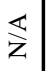 & N & $N$ & 0 & $\overleftrightarrow{\mathrm{z}}$ & 0 & $\mathbb{z}$ & 0 & $\$$ & in & 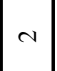 & $\sim$ & $\stackrel{n}{n}$ \\
\hline & $\infty$ & - & 0 & - & N & $N$ & 8 & 0 & $N$ & & 0 & $\sim$ & & & & 0 & $\overleftrightarrow{\mathrm{Z}}$ & 0 & & 0 & ה & $\sim$ & $\sim$ & f \\
\hline & $r$ & $N$ & 0 & $N$ & $N$ & $\sim$ & $\triangleright$ & $\sim$ & $\overleftrightarrow{Z}$ & & $\sim$ & $\mathbb{Z}$ & & - & 0 & $\overleftrightarrow{z}$ & $\mathrm{~N}$ & $\mathbb{z}$ & 0 & 0 & in & $\mathrm{N}$ & $\alpha$ & 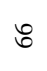 \\
\hline & 0 & $N$ & 0 & - & 0 & 0 & m & $\sim$ & $\overleftrightarrow{z}$ & - & - & $\overleftrightarrow{\mathrm{z}}$ & - & 0 & 0 & $\mathbb{Z}$ & $\sim$ & $\overleftrightarrow{z}$ & $\sim$ & 0 & in & $\mathrm{N}$ & 0 & 寸 \\
\hline 5 & in & 0 & 0 & 0 & 0 & $N$ & ते & 0 & $\overleftrightarrow{\measuredangle}$ & 0 & $\sim$ & $\overleftrightarrow{\mathrm{z}}$ & $N$ & 0 & 0 & $\mathbb{Z}$ & 0 & $\mathbb{z}$ & 0 & 0 & $\approx$ & $\sim$ & $N$ & $\bar{m}$ \\
\hline & T & 0 & $N$ & 0 & 0 & $N$ & q & $\sim$ & 0 & . & $\sim$ & 0 & 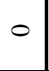 & . & 0 & - & - & 0 & 0 & 0 & $\hat{\imath}$ & $\overleftrightarrow{\mathrm{z}}$ & $\overleftrightarrow{\mathrm{z}}$ & $\bar{m}$ \\
\hline & $m$ & $N$ & $\sim$ & $\sim$ & - & $N$ & \& & 0 & - & 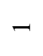 & $\sim$ & - & - & . & 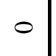 & - & - & 0 & 0 & 0 & $\bar{m}$ & - & - & $\stackrel{\infty}{q}$ \\
\hline & $N$ & - & 0 & $\mathrm{~N}$ & - & $\sim$ & $\triangleright$ & 0 & $\alpha$ & & $\alpha$ & $N$ & & $N$ & $\sim$ & $\sim$ & $\mathbb{z}$ & 0 & $\mathbb{z}$ & 0 & 5 & $\sim$ & 0 & 8 \\
\hline & - & $a$ & - & $\sim$ & & & \& & $\sim$ & & & $N$ & $\mathbb{z}$ & & & 0 & $\overleftrightarrow{\mathrm{z}}$ & & $\mathbb{z}$ & 0 & 0 & ले & 0 & $\sim$ & in \\
\hline
\end{tabular}

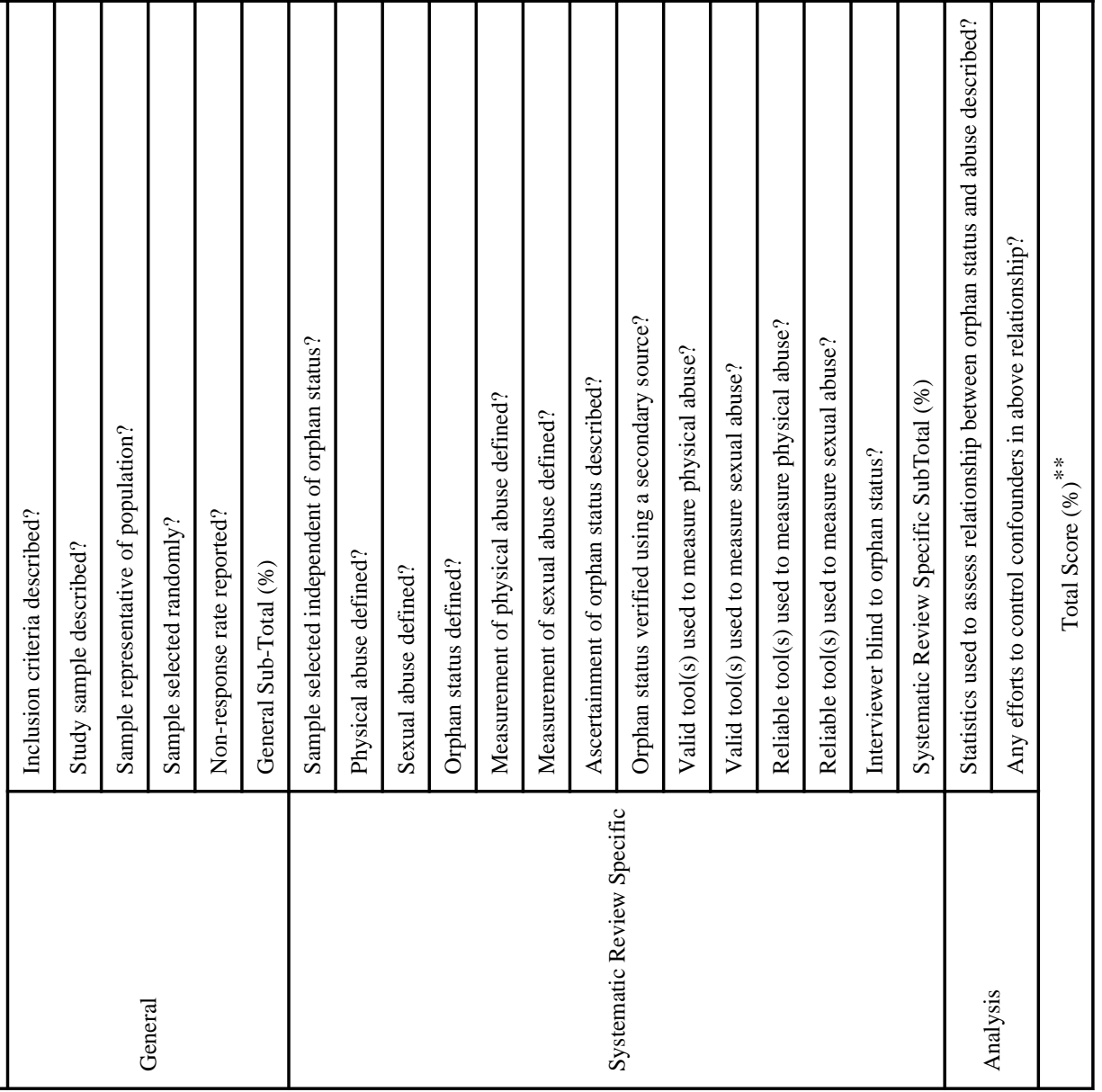


Table 4

A: Forest Plot and Pooled Odds Ratios for Physical Abuse

\begin{tabular}{|c|c|c|c|}
\hline Study \# & OR $(95 \%$ CI $)$ & Weight \% & OR Estimate \\
\hline 2 & $1.10(0.84-1.45)$ & $36 \%$ & \multirow{6}{*}{+} \\
\hline 3 & $0.87(0.68-1.10)$ & $45 \%$ & \\
\hline 4 & $1.13(0.49-2.60)$ & $5 \%$ & \\
\hline 5 & $1.46(0.65-3.26)$ & $5 \%$ & \\
\hline 8 & $0.64(0.35-1.18)$ & $9 \%$ & \\
\hline Overall Estimate & $0.96(0.79-1.16)$ & $100 \%$ & \\
\hline
\end{tabular}

\begin{tabular}{c|c|c|c}
\hline \multicolumn{3}{c|}{ B: Forest Plot and Pooled Odds Ratios for Sexual Abuse } \\
\hline Study \# & OR (95\% CI) & Weight \% & \multirow{2}{*}{ OR Estimate } \\
\hline 1 & $0.91(0.43-1.93)$ & $14 \%$ & $15 \%$ \\
\hline 2 & $0.68(0.34-1.35)$ & $1 \%$ & \\
\hline 4 & $1.04(0.04-25.76)$ & $12 \%$ & \\
\hline 5 & $1.32(0.57-3.09)$ & \\
\hline 6 & $3.75(0.39-36.43)$ & $2 \%$ & \\
\hline 7 & $4.18(1.35-12.98)$ & $8 \%$ \\
\hline 9 & $1.05(0.73-1.51)$ & $27 \%$ \\
\hline 10 & $1.71(1.02-2.86)$ & $21 \%$ \\
\hline
\end{tabular}

\begin{tabular}{c|c|c|c}
\hline \multicolumn{4}{c}{ C: Forest Plot and Pooled Odds Ratios for Forced First Sex } \\
\hline Study \# & OR (95\% CI) & Weight \% & OR Estimate \\
\hline 1 & $0.61(0.35-1.07)$ & 27 & \\
\hline 5 & $0.84(0.29-2.41)$ & 17 & \\
\hline 9 & $2.00(1.18-3.39)$ & 28 & \\
\hline 10 & $1.71(1.02-2.86)$ & 28 & \\
\hline Overall Estimate & $1.20(0.66-2.19)$ & $100 \%$ & \\
\hline
\end{tabular}

